\title{
Functionalization of Natural Cork Composite with Microcapsules after Plasma Treatment
}

\author{
Fernando Ribeiro Oliveira, ${ }^{1}$ Etienne Albino A. Silva, ${ }^{2}$ Sidney Nascimento do Carmo, ${ }^{2}$ \\ Fernanda Steffens, ${ }^{2}$ and António Pedro Garcia de Valadares Souto ${ }^{2}$ \\ ${ }^{1}$ Department of Textile Engineering, Federal University of Rio Grande do Norte, Center of Technology, 59078-970 Natal, RN, Brazil \\ ${ }^{2}$ Department of Textile Engineering, University of Minho, Azurem Campus, 4800-058 Guimarães, Portugal
}

Correspondence should be addressed to António Pedro Garcia de Valadares Souto; souto@det.uminho.pt

Received 28 February 2014; Accepted 7 April 2014; Published 13 May 2014

Academic Editor: Vladimir Tsukruk

Copyright (C) 2014 Fernando Ribeiro Oliveira et al. This is an open access article distributed under the Creative Commons Attribution License, which permits unrestricted use, distribution, and reproduction in any medium, provided the original work is properly cited.

\begin{abstract}
This research aims to study the chemical and physical modifications of natural cork agglomerate after plasma treatment using dielectric barrier discharge (DBD). Different experimental techniques were used to evaluate the surface alterations of the pretreated samples with DBD plasma, as well as the adsorption and adhesion of microcapsules in the substrate, namely, static and dynamic contact angle, surface energy, energy dispersive spectroscopy (EDS), Fourier transform infrared spectroscopy (FTIR), differential scanning calorimetry (DSC), and scanning electron microscopy (SEM). Plasma discharge greatly increases the wettability and surface energy of the samples. Chemical and physical analyses of the cork agglomerate confirmed considerable surface modification. All these surface changes of the cork after plasma treatment led to a remarkable increase in microcapsule adsorption and adhesion when compared with the untreated cork sample.
\end{abstract}

\section{Introduction}

Cork is a product of natural origin, obtained from the cork oak Quercus suber L. The product extracted from the cork oak has excellent physical and chemical characteristics, such as resilience and elasticity, impermeability to liquids and gases, heat, sound, and vibration insulation, low heat conductivity, and antiallergic properties. In addition to this, cork has good dimensional stability and is $100 \%$ recyclable and reusable. These characteristics make this raw material suitable for various uses in different applications, namely, stoppers, fishing poles and buoys, buildings, military shoes, and the automotive industries, among others [1-3].

Despite these numerous possibilities, Portugal the largest producer with about $50 \%$ of world production is limited to the manufacturing of stoppers. This restricted production generates around $85 \%$ wastage [4].

Cork agglomerate is a special material obtained from waste stoppers that can be used in different fields, namely, the textile industry, civil engineering, and architecture, among others, to make products such as clothes, fashion accessories, and cork panels for interior walls and outer wall insulation. Its unique properties also make this material very important for use in protection against cold temperatures. However, the use of cork agglomerate alone is not ideal due its poor mechanical properties. Therefore, sometimes it is necessary to create composites with other types of materials, for example, fabrics or membranes. Thus, the composite can create a material with distinctive properties such as good tensile strength, resistance to tearing, breathability, and impermeability, which are important to increase its range of applicability.

Furthermore, a growing interest in materials with new properties and added value has been encouraging the industry to use final finishes such as the application of microencapsulation. In fact, the use of microcapsules was increased in several different areas, namely, in pharmaceuticals, cosmetics, fragrances, dyes, foods, and textiles, among others [5]. Microencapsulated products are expensive and the final results should meet customer demand. For this reason, it is important that they are able to remain fixed in the 


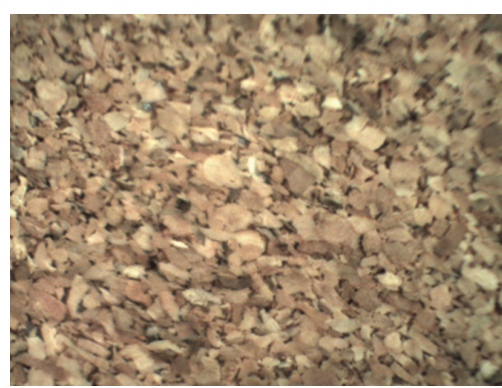

(a)

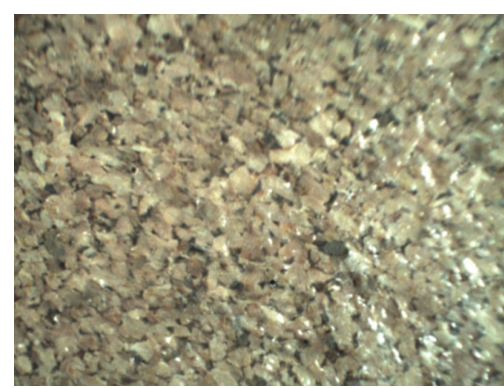

(b)

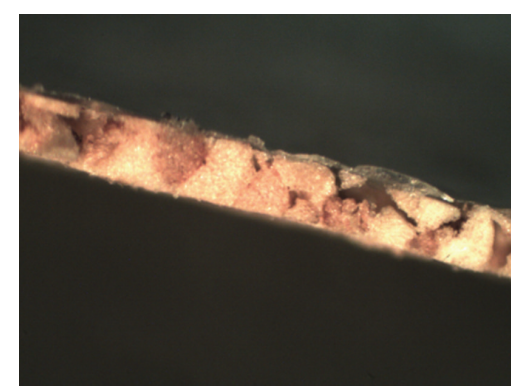

(c)

FIgURE 1: Cork agglomerate laminated (a) cork side, (b) membrane side, and (c) cross section.

substrate after multiple washings and friction cycles [6]. A well-established type of microcapsules is known as phase change material (PCM). The PCM interactively respond to each individual physiological condition, absorb, store, and release heat helping a specific environment or the body to remain comfortable. Its application in cork agglomerate can add value to these substrates making them more efficient in extreme weather conditions. Moreover, the use of PCM microcapsules can simulate the efficacy of other functionalities obtained by microencapsulation technology, such as thermochromism or photochromism, because this material can be easily measured by using a fast and simple technique (differential scanning calorimetry) before and after washing cycles.

Cork has many favourable characteristics as a conceptual product [7], but there is a restriction on the use of this substrate for more elaborate products due to its low surface energy. One way of increasing its usage would be to apply specific treatments that may increase the surface energy, guaranteeing a functional finish.

Chemical treatments that change the surface properties of different materials have sometimes been successful in improving the interfacial bonding [8]. Nevertheless, problems related to the high cost of the treatment and the disposal of chemical products in addition to the increasing concern about environmental pollution have limited extensive industrial application of chemical surface treatments [9].

Plasma technology is considered a clean dry process with an enormous environmental potential to modify the surface of several materials without affecting its bulk properties [8, 10]. In plasma processing, it is well established that exposure to plasmas generated in inert and reactive gases can clean the surface of materials and change their properties, particularly their surface energy [6].

This work intends to study the chemical and physical modifications of natural cork agglomerate after plasma treatment using dielectric barrier discharge, checking its influence on the adsorption and adhesion of phase change materials (PCM) microcapsules applied in this substrate, and also to verify other potential applications for cork oak substrate. The experiments were conducted to determine the effects of plasma treatments on the measured changes to surface, wettability, morphology, and chemical composition.

\section{Materials and Methods}

2.1. Materials. A cork agglomerate laminated with a polymer membrane (chemical base-copolymer polyamide (COPA)) with $105 \mathrm{~g} \cdot \mathrm{m}^{-2}$ and $0.62 \mathrm{~mm}$ thickness was used in this work (Figure 1). The PCM utilized was a melamine microcapsule agent (PRETHERMO C-25) produced by Daiwa Chemical Industries Co. Ltd. The PRETHERMO C-25 is a melamine microcapsule agent with a higher aliphatic hydrocarbon, which is the thermal storage agent. In order to bind the PCM microcapsules to the substrate, an acrylic binder agent was applied. The microcapsules in a water solution were impregnated into the surface of the cork agglomerate material, both untreated and DBD plasma treated, by a padding process in a laboratory foulard with the parameters pressure 4 bar and velocity $6 \mathrm{~m} \mathrm{~min}^{-1}$. Finally, the samples were cured in a laboratory oven for 2 minutes at $150^{\circ} \mathrm{C}$. The following recipe was used: PCM microcapsules- $160 \mathrm{~g} \cdot \mathrm{L}^{-1}$, Binder $-50 \mathrm{~g} \cdot \mathrm{L}^{-1}$, and $\mathrm{MgCl}_{2}-5 \mathrm{~g} \cdot \mathrm{L}^{-1}$.

\subsection{Methods}

2.2.1. Plasma Treatment. The plasma treatment of the cork agglomerate material was carried out at atmospheric pressure with the dielectric barrier discharge plasma (Softal/University of Minho patented prototype) [11]. The machine has a metallic electrode coated with ceramic, a metallic counter electrode coated with silicone, an electric generator, and a high tension transformer. The feeding speed of the plasma machine $(v)$ and power $(P)$ are variable and the sample passes through the electrodes continuously. The plasma dosage can be defined according to (1) [11]:

$$
\text { dosage }=\frac{N \cdot P}{v \cdot w}
$$

where $N$ is the number of passages; $P$ is the power, $\mathrm{W}$; $v$ is the velocity, $\mathrm{m} \mathrm{min}^{-1} ; w$ is the width, $0.5 \mathrm{~m}$. For the treatment of cork agglomerate material, velocity and power were maintained constant and the number of passages was varied.

Table 1 shows the parameters employed for the treatments. 
TABLE 1: Parameters and plasma dosages applied to cork agglomerate material.

\begin{tabular}{lcccc}
\hline Samples & Velocity $\left(\mathrm{m} \mathrm{min}^{-1}\right)$ & Power $(\mathrm{W})$ & Number of passages & Dosage $\left(\mathrm{W}\right.$ min $\left.\mathrm{m}^{-2}\right)$ \\
\hline 1 & 5 & 750 & 1 & 300 \\
2 & 5 & 750 & 2 & 600 \\
3 & 5 & 750 & 4 & 1200 \\
4 & 5 & 750 & 8 & 2400 \\
5 & 5 & 750 & 16 & 4800 \\
\hline
\end{tabular}

2.2.2. Contact Angle, Work of Adhesion, and Surface Energy. Dataphysics equipment using (OCA) software with a video system to capture the images has been used for the measurement of static (initial contact between drop and material) and dynamic contact angles (measurement of the contact angle of the drop with the samples during the time) and for calculation of the cork agglomerate surface free energy. A drop of $5 \mu \mathrm{L}$ different liquids was put on the cork material surface with a microliter syringe and observed with a special CCD camera. At least five measurements at different places were taken for each sample. The camera takes an image every 0.04 second.

The work of adhesion $\left(W_{\text {Adh }}\right)$ was calculated by means of water contact angle evaluation, average values $(\theta)$ and surface energy of distilled water $(\gamma l)$, according to (2) [12]:

$$
W_{\text {Adh }}=\gamma_{l}(1+\cos \theta) \text {. }
$$

For polar solids or liquids the total surface energy is a sum of the always existing London dispersion forces $\left(\gamma^{\mathrm{D}}\right)$ with intermolecular interactions that depend on the chemical nature of the material, compiled as polar forces $\left(\gamma^{\mathrm{P}}\right)$ by (3) [13]:

$$
\gamma=\gamma^{\mathrm{D}}+\gamma^{\mathrm{P}}
$$

The polar and dispersive components of the surface energy were calculated using the $\mathrm{Wu}$ method (harmonicmean), by (4) [14]:

$$
\gamma_{\mathrm{sl}}=\gamma_{\mathrm{s}}+\gamma_{1}-4\left[\frac{\gamma_{\mathrm{s}}^{\mathrm{D}} \gamma_{1}^{\mathrm{D}}}{\gamma_{\mathrm{s}}^{\mathrm{D}}+\gamma_{1}^{\mathrm{D}}}+\frac{\gamma_{\mathrm{s}}^{\mathrm{P}} \gamma_{1}^{\mathrm{P}}}{\gamma_{\mathrm{s}}^{\mathrm{P}}+\gamma_{1}^{\mathrm{P}}}\right] .
$$

Since calculation of surface energy requires at least two liquids, three different liquids with known surface energy $\left(\mathrm{mJ} \cdot \mathrm{m}^{-2}\right)$ and surface energy components $\left(\mathrm{mJ} \cdot \mathrm{m}^{-2}\right)$ were used in this study as follows.

Distilled water (Y: 72.8; $\left.\gamma^{\mathrm{D}}: 29.1 ; \gamma^{\mathrm{P}}: 43.7\right)$, polyethylene glycol 200 (PEG) (Y: 43.5; $\left.\gamma^{\mathrm{D}}: 29.9 ; \gamma^{\mathrm{P}}: 13.6\right)$, and glycerol (Y: $\left.63.4 ; \gamma^{\mathrm{D}}: 37.4 ; \gamma^{\mathrm{P}}: 26.0\right)[15]$.

\subsubsection{Fourier Transform Infrared and Energy Dispersive Spec-} troscopy. A Nicolet Avatar 360 (FTIR) spectrophotometer using an attenuated total reflectance accessory (ATR) was employed to record the FTIR spectra of the cork agglomerate samples. The IR spectra were collected at a spectrum resolution of $16 \mathrm{~cm}^{-1}$, over a range of $400-4000 \mathrm{~cm}^{-1}$ at room temperature.

The surface chemical composition of PCM, before and after plasma modification, was determined by EDS using an EDAX Si (Li) detector and an acceleration voltage of $5 \mathrm{kV}$.
2.2.4. Scanning Electronic Microscopy. The surfaces of the plasma treated and the PCM coated samples were observed with an ultra-high resolution field emission gun scanning electron microscopy (FEG-SEM), NOVA 200 Nano (SEM), (FEI) Company. Samples for SEM measurements were coated with Au employing a Sputter Coater Bal-Tec SCD 005.

2.2.5. Differential Scanning Calorimetry. Mettler Toledo DSC822 equipment was used in order to analyse the treated and untreated plasma substrates and to quantify the PCM energy adsorption of these samples after and before the washing test. The DSC thermal analyses were performed under inert nitrogen atmosphere at $20 \mathrm{~mL} \mathrm{~min}^{-1}$ flow rate,

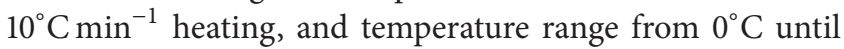
$50^{\circ} \mathrm{C}$.

2.2.6. Washing Fastness. To test the durability of PCM bonding after washing, the cork agglomerate substrate was submitted in cycles of 1 and 5 in a Linitest Original Hanau C1-20 for $30 \mathrm{~min}$ at $40^{\circ} \mathrm{C}$, in accordance with ISO Standard 105-C06 A1S.

\section{Results and Discussion}

3.1. Static and Dynamic Contact Angle. The static and dynamic contact angle results, using water drop, showed a significant difference when comparing the samples with and without plasma treatment (Figure 2(a)). The static contact angle for the cork agglomerate material without plasma treatment was $125.5^{\circ}$, being considered as hydrophobic. The static contact angle $\left({ }^{\circ}\right)$ variation of the water drop $(5 \mu \mathrm{L})$ is highly dependent on the plasma dosage applied. Contact angle measurements show a decrease after DBD plasma treatment, falling to $25.9^{\circ}$ when the dosage of $4800 \mathrm{~W} \cdot \mathrm{min} \cdot \mathrm{m}^{-2}$ is applied, which correspond to higher hydrophilicity. These results suggest that the surface of the plasma-treated samples has been significantly changed due the interaction between active species of the plasma and cork surface.

Sometimes it is very difficult to measure static contact angle in natural substrates, due to the absorbency and porosity of these materials and their irregular structure. In such cases, wicking or dynamic contact angle can be used to provide information about the wetting properties of these materials.

The dynamic contact angle measurements of the samples untreated and treated with different dosages can be observed in Figure 2(b). The results obtained show that the wettability 


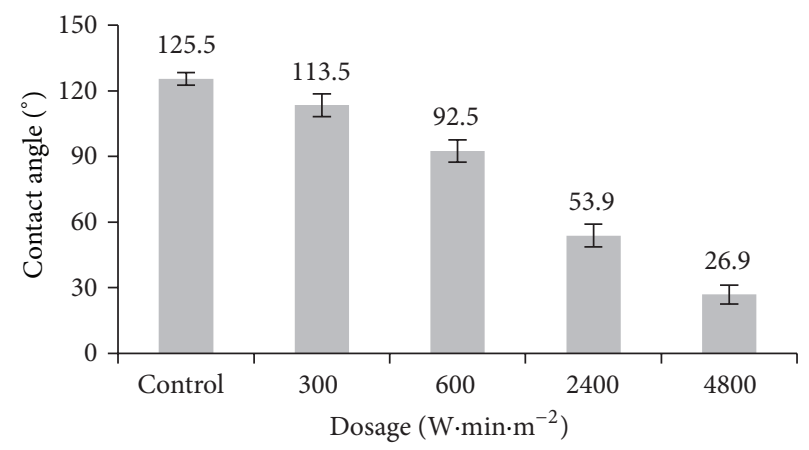

(a)

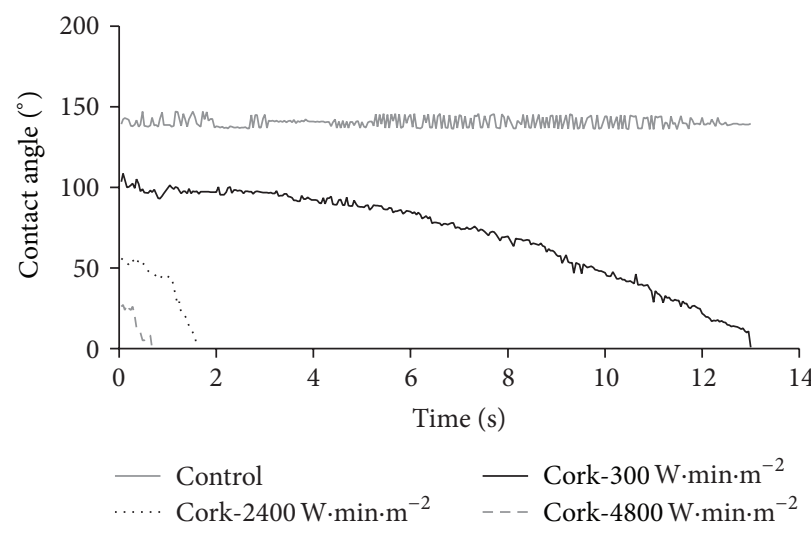

(b)

Figure 2: Static (a) and dynamic (b) contact angle of cork agglomerate.

TABLE 2: Surface energy and work of adhesion (distilled water) in the cork samples with and without plasma treatment.

\begin{tabular}{|c|c|c|c|c|c|c|c|}
\hline & $\theta_{\text {water }}\left({ }^{\circ}\right)$ & $\theta_{\mathrm{PEG}}\left({ }^{\circ}\right)$ & $\theta_{\text {glycerol }}\left({ }^{\circ}\right)$ & $\gamma \mathrm{mJ} \cdot \mathrm{m}^{-2}$ & $\gamma^{\mathrm{D}} \mathrm{mJ} \cdot \mathrm{m}^{-2}$ & $\gamma^{\mathrm{P}} \mathrm{mJ} \cdot \mathrm{m}^{-2}$ & $W_{\text {adh }}$ \\
\hline Untreated & 125.5 & 100.2 & 137.2 & 10.9 & 7.4 & 3.5 & 30.52 \\
\hline $600 \mathrm{~W} \cdot \mathrm{min} \cdot \mathrm{m}^{-2}$ & 92.5 & 70.6 & 132.9 & 17.1 & 4.4 & 12.7 & 69.62 \\
\hline $2400 \mathrm{~W} \cdot \mathrm{min} \cdot \mathrm{m}^{-2}$ & 53.9 & 70.8 & 116.0 & 26.9 & 2.5 & 24.4 & 115.69 \\
\hline $4800 \mathrm{~W} \cdot \mathrm{min} \cdot \mathrm{m}^{-2}$ & 26.9 & 65.4 & 117.2 & 35.5 & 10.0 & 25.5 & 137.72 \\
\hline
\end{tabular}

of the cork agglomerate is highly improved by the increase of plasmatic dosage.

As the drop hits the surface it spreads, reaching the static contact angle $(\theta)$. Then the water drop starts to be absorbed by the cork agglomerate decreasing its volume steadily, and thus decreasing the contact angle until complete drop adsorption is achieved. As can be observed, a faster decrease of contact angle was observed for the cork substrate treated with a higher dosage of plasma. Similar results have been reported in the literature for different synthetic and natural materials, mentioning modifications in accessible polar groups at the surface and creation of microporosity as the main reasons for the increase in water adsorption velocity $[16,17]$.

3.2. Surface Energy and Work of Adhesion. Double barrier dielectric plasma is very effective on the increase of the surface energy of different materials, not only by chemical conversion of the surface but often simply also through the plasma cleaning process. In a cleaning process, inert and oxygen plasmas are used. Plasma is able to remove, via ablation, organic contaminants, either natural or added, on the materials, increasing surface energy and improving the wettability of the substrate [18].

Using water, PEG, and glycerol contact angle values, the total surface energy $(\gamma)$, dispersive component $\left(\gamma^{\mathrm{D}}\right)$, and polar component $\left(\gamma^{\mathrm{P}}\right)$ were calculated and the results are shown in Table 2.

Total surface energy significantly increases after DBD plasma treatment. Initially the dispersive and polar components of the cork agglomerate without treatment were $7.4 \mathrm{mJm}^{-2}$ and $3.5 \mathrm{mJm}^{-2}$, respectively. For the dosage of
$4800 \mathrm{~W} \cdot \mathrm{min} \cdot \mathrm{m}^{-2}$, the dispersive component increased to $10.0 \mathrm{~mJ} \cdot \mathrm{m}^{-2}$ and the polar component registered a huge increase of up to $25.5 \mathrm{~mJ} \cdot \mathrm{m}^{-2}$.

These results can be explained by partial decomposition of the hydrophobic layer after DBD plasma treatment caused by the etching process and the formation of new polar groups on the cork agglomerate surface [19].

Furthermore, the result of adhesion of the cork substrate after plasma treatment has increased significantly. The polar functional groups formed by means of plasmatic treatment can become the external substances which easily attach to the cork agglomerate material.

Moreover, in Table 2 it can also be observed that the result of adhesion enhanced by the increase of plasmatic dosage went from $30.5 \mathrm{~mJ} \cdot \mathrm{m}^{-2}$ (untreated sample) to $137.7 \mathrm{~mJ} \cdot \mathrm{m}^{-2}$ $\left(4800 \mathrm{~W} \cdot \mathrm{min} \cdot \mathrm{m}^{-2}\right)$. Therefore, DBD plasma treatment can be considered an interesting solution to promote the functional performance of different materials $[8,10,18]$.

\subsection{Fourier Transform Infrared (FITR) and Energy Dispersive} Spectroscopy (EDS). Figure 3(a) shows the infrared spectra of cork agglomerate substrate in which some of the most significant peaks were seen: $3348 \mathrm{~cm}^{-1}$ can be accredited to the $\mathrm{O}-\mathrm{H}$ stretching, 2926 and $2850 \mathrm{~cm}^{-1}, n \mathrm{CH}$ of mostly suberin aliphatic chains; $1735 \mathrm{~cm}^{-1}, n \mathrm{CO}$ of suberin ester groups; 1635 and $723 \mathrm{~cm}^{-1}$, suberin $\mathrm{R}_{1} \mathrm{CH}=\mathrm{CHR}_{2}$ groups; 1607 and $1513 \mathrm{~cm}^{-1}, n \mathrm{C}=\mathrm{C}$ of lignin aromatics [20, 21].

FTIR results also provided evidence of changes in the chemical constituents with plasma treatment mainly in the bands at 2926 and $2850 \mathrm{~cm}^{-1}$ which show a lower intensity as opposed to the treated samples, $1735 \mathrm{~cm}^{-1}$ (carbonyl bonds), 


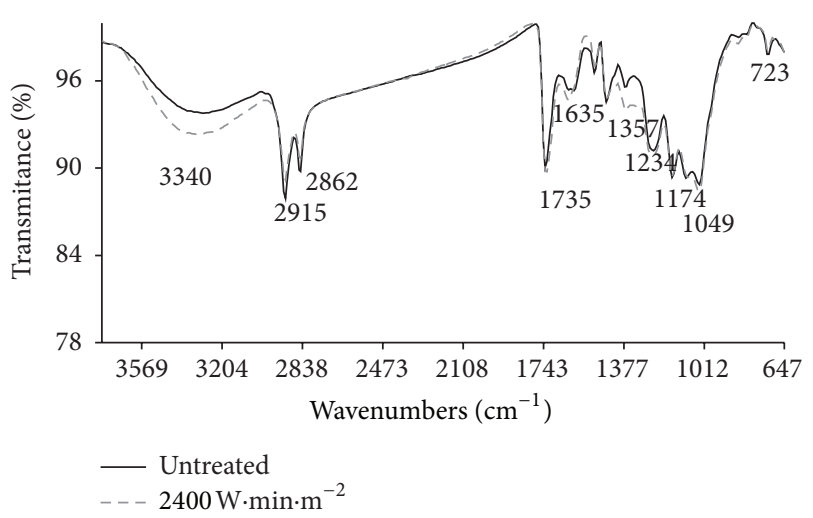

(a)

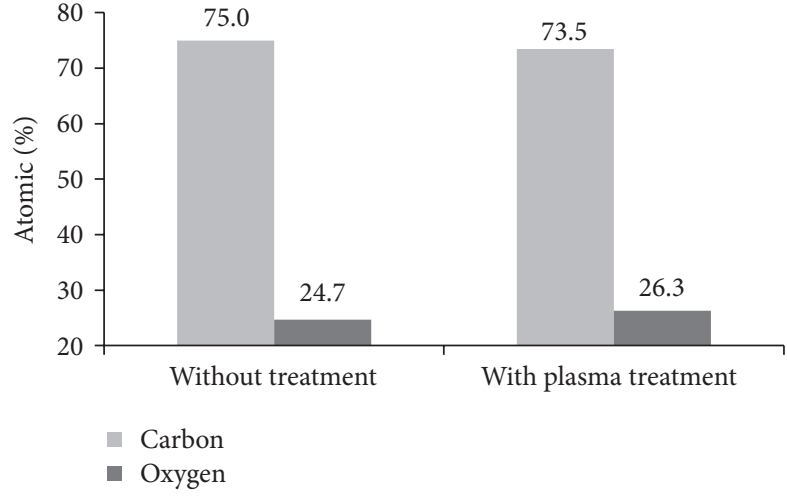

(b)

FIGURE 3: FTIR-ATR (a) and atomic percentage by EDS (b) of the cork agglomerate samples untreated and plasma treated $\left(2400 \mathrm{~W} \cdot \mathrm{min} \cdot \mathrm{m}^{-2}\right)$.

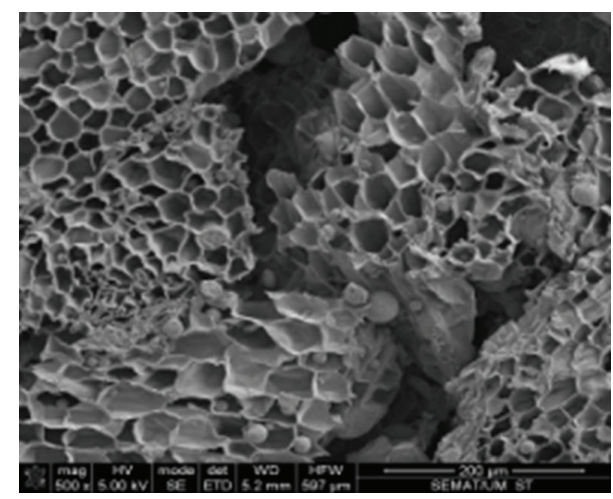

(a)

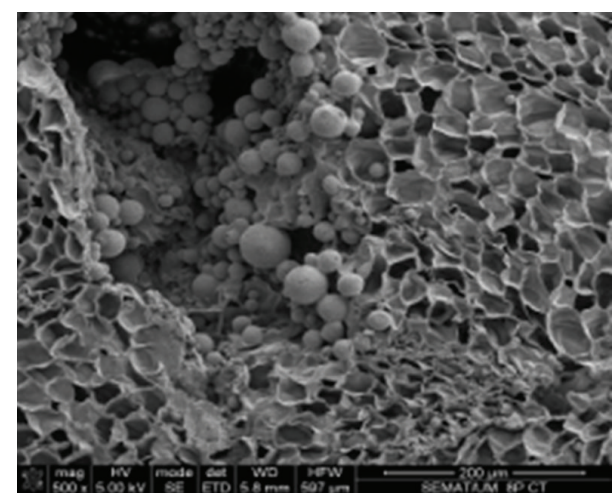

(b)

FIGURE 4: Images of PCM microcapsules fixed on the cork substrate untreated (a) and plasma treated-2400 W.min $\cdot \mathrm{m}^{-2}(\mathrm{~b})$.

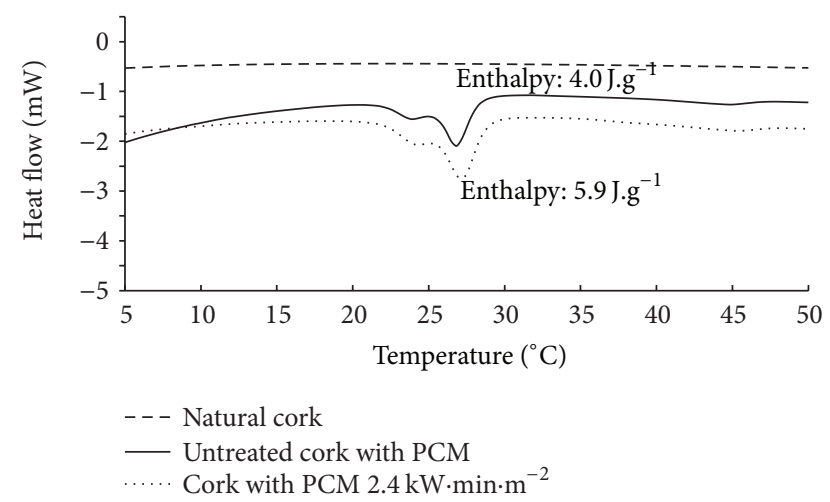

FIGURE 5: DSC thermograms of the untreated and plasma-treated cork material with padded PCM microcapsules.

$1357 \mathrm{~cm}^{-1}(\mathrm{C}-\mathrm{N})$, and $1010-1300 \mathrm{~cm}^{-1}$ bands (carbohydrate and lignin $\mathrm{C}-\mathrm{O}$ bond) which show a higher intensity peak after the plasmatic dosage was applied. The interaction between DBD plasma species and cork agglomerate leads to an increased amount of the polar oxygen and nitrogen groups onto the surface [21].

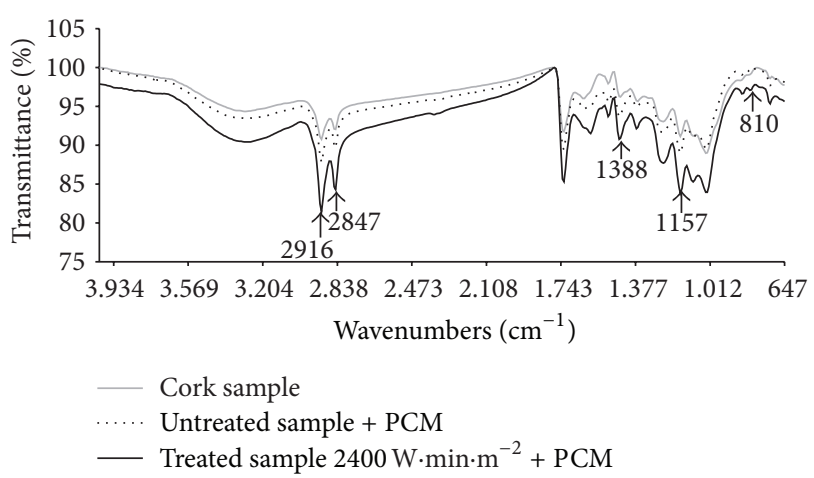

FIGURE 6: FTIR spectra of cork agglomerate composite (cork sample), cork with PCM microcapsules, and plasma-treated cork with PCM microcapsules.

The effect of the plasma treatment on functional groups of cork agglomerate material was also qualitatively observed by EDS analysis using the acceleration voltage of $5 \mathrm{kV}$. The results indicate an increase of oxygen/carbon ratio $(\mathrm{O} / \mathrm{C})$ from 0.33 to 0.36 , which is responsible for enhancing the 


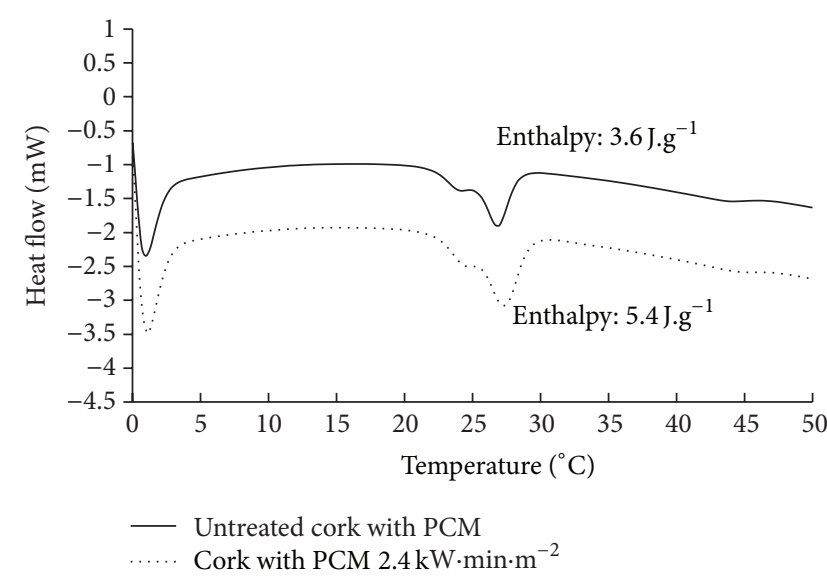

(a)

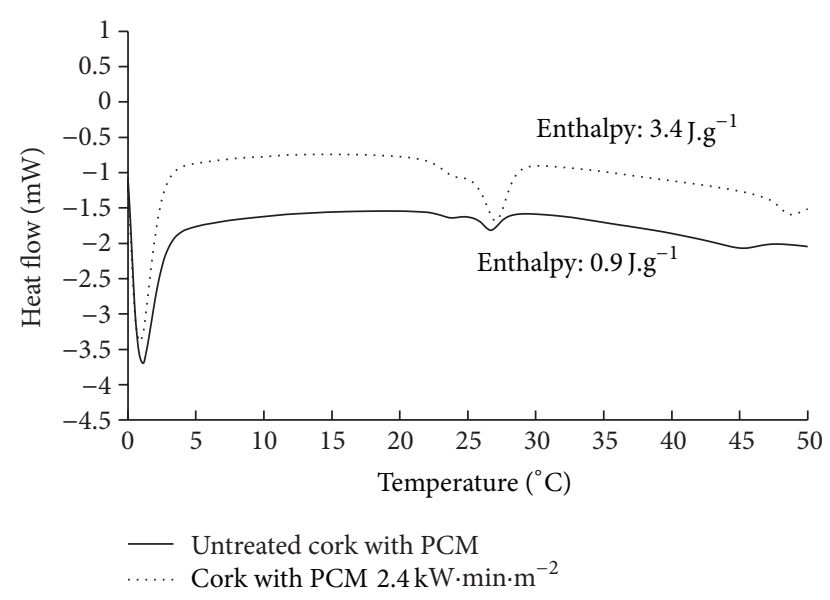

(b)

FIGURE 7: DSC thermograms of the untreated and plasma-treated cork material with PCM microcapsules after 1 (a) and 5 washing cycles (b).

content of hydrophilic functional groups on the cork surface. Figure 3 shows the elemental composition of the untreated samples and plasma-treated samples $\left(2400 \mathrm{~W} \cdot \mathrm{min} \cdot \mathrm{m}^{-2}\right)$.

The results obtained by differential scanning calorimetry and scanning electronic microscopy techniques showed no major structural change in the cork material after plasma application. These results demonstrate evidence that DBD plasma treatment can modify the surface of cork agglomerate material without changing its bulk properties or appearance.

3.4. Scanning Electronic Microscopy. Figure 4 shows the SEM images of untreated and plasma-treated samples, padded with PCM microcapsules. It is possible to observe that several microcapsules are adsorbed on the surface of the samples. These results confirm that DBD plasma can be used to modify the surface of the cork agglomerate, leading to enhanced hydrophilicity. Due to these modifications it is possible to increase the adsorption of the PCM microcapsules on the cork surface $[22,23]$.

3.5. Differential Scanning Calorimetry. Figure 5 shows the differences in the energy storage capacity of the coated cork/membrane by comparing the samples with and without plasma treatment. The evaluation of the amount of PCM microcapsules that were adsorbed by the material was done by means of enthalpy. An increase in the energy storage capacity in the samples treated with plasma went from $4.0 \mathrm{~J} \cdot \mathrm{g}^{-1}$ (untreated sample) to $5.9 \mathrm{~J} \cdot \mathrm{g}^{-1}\left(2400 \mathrm{~kW} \cdot \mathrm{min} \cdot \mathrm{m}^{-2}\right)$. This result confirmed that plasma treatment increased the adsorption capacity with regard to the PCM microcapsules.

3.6. Fourier Transform Infrared Spectroscopy. Oliveira et al. [6] noticed the appearance of four characteristic peaks of the melamine microcapsules. These peaks were $\mathrm{N}-\mathrm{H}$ stretching vibrations at about $2920 \mathrm{~cm}^{-1}, \mathrm{C}-\mathrm{H}$ stretching vibrations at about 2840, $1386 \mathrm{~cm}^{-1}$, and $\mathrm{C}-\mathrm{O}$ stretching vibrations at about $1160 \mathrm{~cm}^{-1}$. The band at $810 \mathrm{~cm}^{-1}$ is also a characteristic of the melamine PCM corresponding to the bending vibration of a triazine ring [24].

Figure 6 shows FTIR spectra of the following samples: natural cork (control), cork with PCM melamine microcapsules, and plasma-treated cork with PCM melamine microcapsules. The FTIR analysis confirms the higher amount of PCM microcapsules adsorbed on this composite material pretreated with plasma DBD.

3.7. Effect of the DBD Plasma Discharge on PCM Microcapsule Adhesion. Figure 7 shows the DSC curves of the untreated and DBD-plasma-treated cork padded with PCM microcapsules after 1 to 5 washing cycles. As can be verified, the adhesion of the PCM microcapsules in the plasma-treated cork agglomerate substrate increased considerably.

In the untreated substrate, the enthalpy decreased $10 \%$ and $78.5 \%$ after 1 and 5 washing cycles, respectively. On the other hand in the DBD-treated substrate the enthalpy only decreased $8.5 \%$ and $42.4 \%$ after 1 and 5 washing cycles. The enthalpy of the treated sample after the fifth washing cycle $\left(3.4 \mathrm{~J} \cdot \mathrm{g}^{-1}\right)$ was approximately four times higher than that of the sample without treatment $\left(0.9 \mathrm{~J} \cdot \mathrm{g}^{-1}\right)$.

Activating the surface by DBD plasma treatment will enhance the interaction of the adhesive with the surface of the cork substrate and provide anchor sites for the binder/microcapsules solution.

\section{Conclusions}

This study has proved that the surface modification of cork agglomerate by DBD plasma treatment can create more polar groups and increase the surface energy, wettability, and the outcome of adhesion of the samples, which is responsible for improving the interaction of this substrate with finishing products and polymeric resins.

Therefore, the degree of wettability provides the best conditions for development of the products used in textile finishing, such as dyeing (dyes), printing (pigment), or even 
microcapsules and nanoparticles, among others. Thus, this better interaction with different materials, adding higher functionality, usability, comfort, and aesthetic values, can allow the use of cork products in various ways in the textile, architecture, and fashion industries.

All these modifications of the cork agglomerate after plasma treatment led to a remarkable increase in microcapsule adsorption and adhesion to the materials during finishing when compared to untreated samples. When DBD treatment was applied to the cork agglomerate composite the microcapsules were successfully fixed even after 5 washing cycles.

Plasma technology can be considered an excellent solution for providing certain material surface characteristics without sacrificing the primary engineering qualities of the material. This technology is capable of modifying the surface of a material only a few molecules deep and promoting the functional performance of several finishing products, achieving more adsorption and durable properties that contribute to the sustainability of the innovative materials.

\section{Conflict of Interests}

The authors declare that there is no conflict of interests regarding the publication of this paper.

\section{Acknowledgments}

The authors gratefully acknowledge the CsF-CNPq and CAPES Foundation, Brazil, for the doctoral Grant nos. 202539/2011-3, BEX0978/12-4, and BEX18645/12-7. They would also like to thank the Project no. 2011/19280 (“COLTEC”), FCT, and FEDER-COMPETE funding PEt-C/ CTM/UI0264/2011.

\section{References}

[1] P. Jové, M. À. Olivella, and L. Cano, "Study of the variability in chemical composition of bark layers of Quercus Suber L. from different production areas," Bioresources, vol. 6, no. 2, pp. 18061815, 2011.

[2] H. Pereira and A. Costa, Evolução Recente Da Indústria De Cortiça. Centro De Estudos Florestais, Instituto Superior De Agronomia, Universidade Técnica de Lisboa, Lisboa, Portugal, 2002.

[3] F. M. A. Fonseca, "Crescimento e qualidade da cortiça potencialidades da microdesintometria," in Congresso Florestal Nacional, Universidade De Trás-os Montes E Alto Douro, 15 A $17 D E z$, pp. 267-271, Anais do III Congresso Florestal Nacional, 1994.

[4] A. Schmidt, Cortiça E Artigos dE Cortiça, Banco de Fomento Nacional, Lisboa, Portugal, 1983.

[5] G. Nelson, "Application of microencapsulation in textiles," International Journal of Pharmaceutics, vol. 242, no. 1-2, pp. 5562, 2002.

[6] F. R. Oliveira, M. Fernandes, N. Carneiro, and A. P. Souto, "Functionalization of wool fabric with phase-change materials microcapsules," Journal of Applied Polymer Science, vol. 128, pp. 2638-2647, 2013.
[7] V. A. Zeithaml, R. T. Rust, and K. N. Lemon, "The customer pyramid: creating and serving profitable customers," California Management Review, no. 4, pp. 118-142, 2001.

[8] F. R. Oliveira, L. Erkens, R. Fangueiro, and A. P. Souto, "Surface modification of banana fibers by DBD plasma treatment," Plasma Chemistry and Plasma Processing, vol. 32, no. 2, pp. 259273, 2012.

[9] Y. Seki, M. Sarikanat, K. Sever, S. Erden, and H. A. Gulec, "Effect of the low and radio frequency oxygen plasma treatment of jute fiber on mechanical properties of jute fiber/polyester composite," Fibers and Polymers, vol. 11, no. 8, pp. 1159-1164, 2010.

[10] N. Carneiro, A. P. Souto, E. Silva et al., "Dyeability of coronatreated fabrics," Coloration Technology, vol. 117, no. 5, pp. 298302, 2001.

[11] N. Carneiro, A. P. Souto, F. Forster, and E. Prinz, 2004, Continuous and semicontinuous treatment of textile materials integrating corona discharge. Patent in internationalization phase patent number PCT/PT2004/000008.

[12] C. Baley, F. Busnel, Y. Grohens, and O. Sire, "Influence of chemical treatments on surface properties and adhesion of flax fibre-polyester resin," Composites A: Applied Science and Manufacturing, vol. 37, no. 10, pp. 1626-1637, 2006.

[13] D. Papakonstantinou, E. Amanatides, D. Mataras, V. Ioannidis, and P. Nikolopoulos, "Improved surface energy analysis for plasma treated PET films," Plasma Processes and Polymers, vol. 4, no. 1, pp. S1057-S1062, 2007.

[14] J. S. Kim, R. H. Friend, and F. Cacialli, "Improved operational stability of polyfluorene-based organic light-emitting diodes with plasma-treated indium-tin-oxide anodes," Applied Physics Letters, vol. 74, no. 21, pp. 3084-3086, 1999.

[15] M. Keller, A. Ritter, P. Reimann, V. Thommen, A. Fischer, and D. Hegemann, "Comparative study of plasma-induced and wetchemical cleaning of synthetic fibers," Surface and Coatings Technology, vol. 200, no. 1-4, pp. 1045-1050, 2005.

[16] J. Molina, F. R. Oliveira, A. P. Souto, M. F. Esteves, J. Bonastre, and F. Cases, "Enhanced adhesion of polypyrrole/ $\mathrm{PWO}^{4} \mathrm{O}^{3-}$-hybrid coatings on polyester fabrics," Journal of Applied Polymer Science, vol. 129, pp. 422-433, 2012.

[17] F. R. Oliveira, A. P. Souto, N. Carneiro, and J. H. O. Nascimento, "Surface modification on polyamide 6.6 with Double Barrier Discharge (DBD) plasma to optimise dyeing process by direct dyes," Materials Science Forum, vol. 636-637, pp. 846-852, 2010.

[18] S. Y. Cheng, C. W. M. Yuen, C. W. Kan et al., "Influence of atmospheric pressure plasma treatment on various fibrous materials: performance properties and surface adhesion analysis," Vacuum, vol. 84, no. 12, pp. 1466-1470, 2010.

[19] E. Bozaci, K. Sever, A. Demir, Y. Seki, M. Sarikanat, and E. Ozdogan, "Effect of the atmospheric plasma treatment parameters on surface and mechanical properties of jute fabric," Fibers and Polymers, vol. 10, no. 6, pp. 781-786, 2010.

[20] S. R. Carmo, [Ph.D. dissertation], University of Aveiro, Portugal, 1997.

[21] M. H. Lopes, N. C. Pascoal, A. S. Barros, D. Rutledge, I. Delgadillo, and A. M. Gil, "Quantitation of aliphatic suberin in quercus suber L. cork by FTIR spectroscopy and solid-state (13)C-NMR Spectroscopy," Biopolymers, vol. 57, no. 6, pp. 344351, 2000.

[22] A. Demir, H. A. Karahan, E. Özdoğan, T. Öktem, and N. Seventekin, "The synergetic effects of alternative methods in wool finishing," Fibres and Textiles in Eastern Europe, vol. 16, no. 2, pp. 89-94, 2008. 
[23] N. Dumitrascu, I. Topala, and G. Popa, "Dielectric barrier discharge technique in improving the wettability and adhesion properties of polymer surfaces," IEEE Transactions on Plasma Science, vol. 33, no. 5, pp. 1710-1714, 2005.

[24] D. J. Merline, S. Vukusic, and A. A. Abdala, "Melamine formaldehyde: curing studies and reaction mechanism," Polymer Journal, vol. 45, pp. 413-419, 2013. 

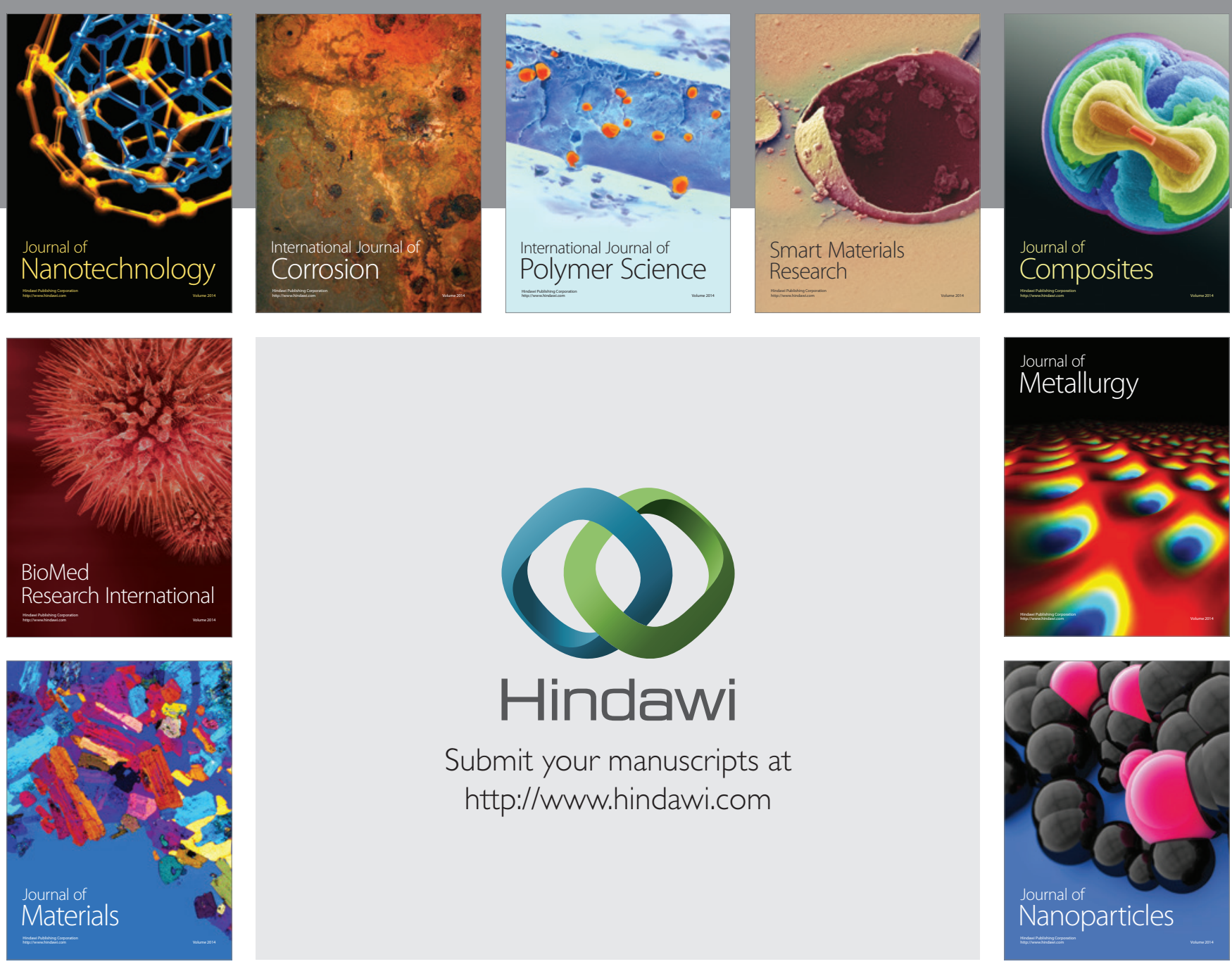

Submit your manuscripts at http://www.hindawi.com
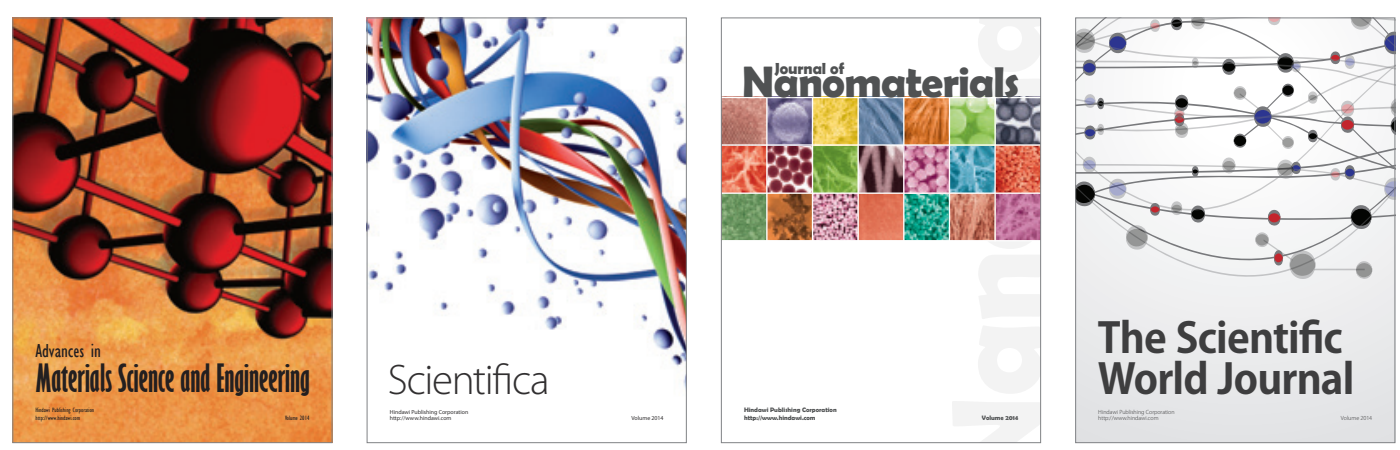

\section{The Scientific World Journal}
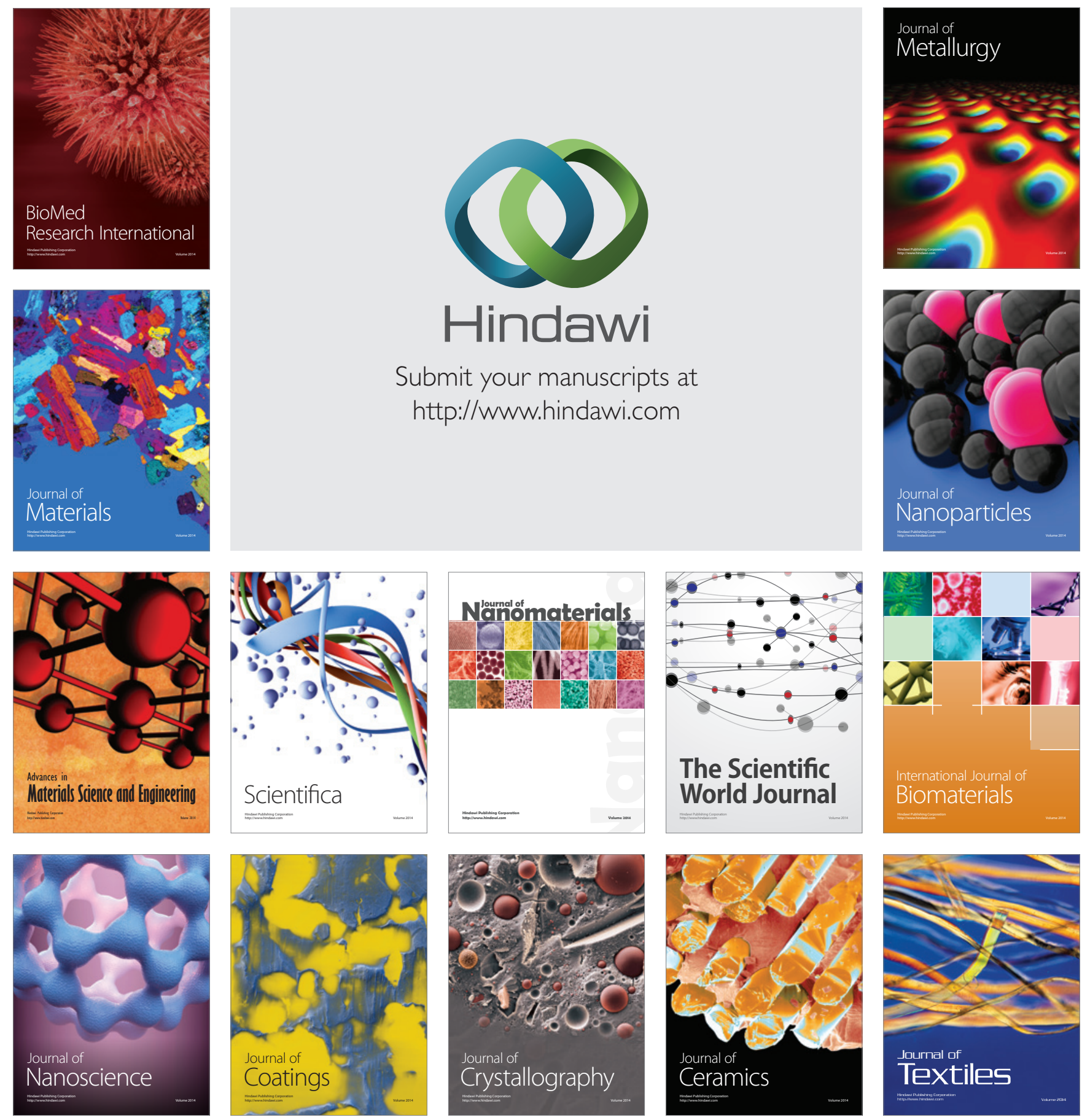